\title{
Formation of Conductive Film Using Sulfonation of Epoxy Laminate
}

\author{
Hidemi NAWAFUNE*, Kohei KUGO*, Shozo MIZUMOTO*, \\ Masaru SEITA** and Masaaki IMANARI**
}

\section{エポキシ樹脂のスルホン化を利用する導電性皮膜の形成}

\author{
縄舟秀美 ${ }^{*}$, 久後行平 ${ }^{*}$, 水本省三*, 清田 優 ${ }^{* *}$, 今成眞明 ${ }^{* *}$
}

\begin{abstract}
Key Words : Epoxy Laminate, Sulfonation, Copper Ion Adsorption, Conductive Film
\end{abstract}
\section{Introduction}

Recently, much importance has been attached to the problem of environmental pollution. The use of the electroless copper plating becomes therefore more and more difficult because of the use of harmful formaldehyde and the wastetreatment of chelating agents. The preparation of the conductive films using a palladium colloid, conductive polymer, and graphite has been employed for manufacture of printed wirering boards ${ }^{11}$.

In this paper, a new method for formation of a copper thin film on an epoxy laminate through sulfonation of the laminate followed by adsorption and reduction of copper ions was investigated.

\section{Experimental}

\section{1 Sulfonation of an epoxy laminte}

Epoxy laminate (Matushita electric works, R1766), which has the following TBPA (tetrabromo bisphenol A) skeletal structure, was used.

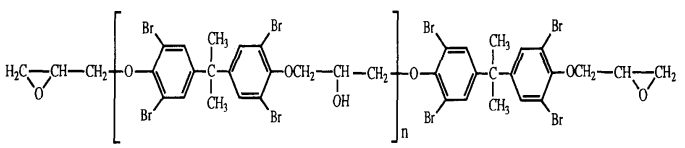

Test samples of the epoxy laminate were dipped in $6-14 \mathrm{M}$ sulfuric acid solutions at $30-60^{\circ} \mathrm{C}$, thoroughly rinsed, and then dried. Sulfonation of the epoxy laminate was confirmed by a Nicolet Magna 750 FTIR spectrometer equipped with a Nic-Plan microscope (Spectra-Tech Inc.) using an ATR Objective (Zinc selenide). ATR spectra in the 2000 to $700 \mathrm{~cm}^{-1}$ were obtained by co-adding 100 scans at $4 \mathrm{~cm}^{-1}$ resolution with a narrow

* Fac. of Sci., Konan Univ. (9-1, Okamoto 8-chome, Higashinada-ku, Kobe-shi, Hyogo 658, Japan) 甲南大学 理学部

** LeaRonal Japan Inc. (269-4, Yoshino-cho 2-chome, Ohmiya-shi, Saitama 330, Japan)

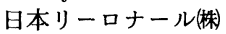

band pass $\mathrm{HgCdTe}$ (MCT) detector.

2. 2 Adsorption and reduction treatment of copper ion

The sulfonated test samples were dipped in $0.05 \mathrm{M}$ copper sulfate solution for three minutes to adsorb the copper ions. After rinsing, the test samples adsorbed copper ions were dipped in sodium tetrahydroborate solution for three minutes, producing a conductive through reduction of the copper ion to form a copper thin film. The surface conductivity of the test sample was measured using a digital multimeter. The adsorbed copper ion was dissolved in 5\% nitric acid solution and measured by atomic absorption spectrometer.

\section{Results and Discussion}

\section{1 Sulfonation of an epoxy laminate}

Fig. 1 shows the FTIR ATR spctra of epoxy laminates untreated and treated with $14 \mathrm{M}$ sulfuric acid at $60^{\circ} \mathrm{C}$ for three minutes. According to these spectra, benzene ring stretching and $\mathrm{C}-\mathrm{H}$

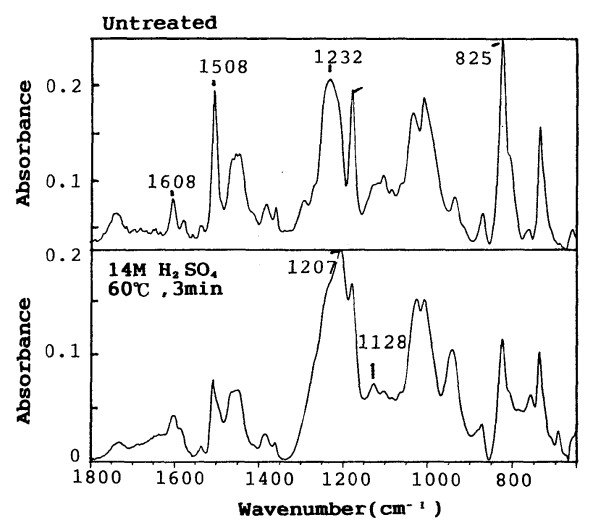

Fig. 1 FTIR ATR spectra of epoxy laminate surface. $1600-1500 \mathrm{~cm}^{-1}$ phenyl $\mathrm{C}=\mathrm{C}$ strech $825 \mathrm{~cm}^{-1} \mathrm{C}-\mathrm{H}$ out-of-plane deformation 1232, $1075-1000 \mathrm{~cm}^{-1}$ ethers $\nu \mathrm{C}-\mathrm{O}$ 1207, $1128 \mathrm{~cm}^{-1}$ sulfo group $\left(\left[\mathrm{H}_{3} \mathrm{O}\right]^{+}\left[\mathrm{RSO}_{3}\right]^{-}\right)$ 


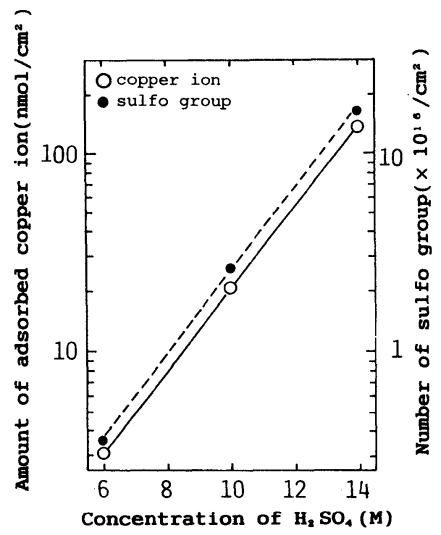

Fig. 2 Changes in adsorbed copper ions and sulfo group on epoxy laminate with sulfuric acid treatment $\left(60^{\circ} \mathrm{C}, 3 \mathrm{~min}\right)$.

out-of-plane bending bands appeared at 1600 to $1500 \mathrm{~cm}^{-1}$ and $825 \mathrm{~cm}^{-1}$, respectively. The ether $\nu \mathrm{C}-\mathrm{O}$ mode of the asymmetric and symmetric stretching appeared at $1232 \mathrm{~cm}^{-1}$ and 1075 to $1000 \mathrm{~cm}^{-1}$ regions, respectively. The intensity of the peak due to the phenyl $\mathrm{C}-\mathrm{H}$ bending decreased with the sulfuric acid treatment, and new peaks assigned to sulfo group appeared at $1207 \mathrm{~cm}^{-1}$ and $1128 \mathrm{~cm}^{-1}$. In general, the sulfo group shows the $\mathrm{SO}_{2}$ asymmetric and symmetric stretching bands in the $1350 \mathrm{~cm}^{-1}$ and $1160 \mathrm{~cm}^{-1}$ regions, however, the absorption peaks in Fig. 1 shifted toward lower frequencies. This peak shift should mean the presence of sulfonic acid oxonium salt $\left(\left[\mathrm{H}_{3} \mathrm{O}\right]^{+}\left[\mathrm{RSO}_{3}\right]^{-}\right)$by hydration of sulfonic acid $^{2)}$. Thus, it is obvious that the sulfo group, as a cation exchange group, was introduced onto the epoxy laminate surface through sulfuric acid treatment.

\section{2 Adsorption and reduction treatment of copper ion}

The epoxy laminates were dipped in sulfuric acid solutions at $60^{\circ} \mathrm{C}$ for three minutes, and then dipped in $0.05 \mathrm{M}$ copper sulfate solution for three minutes to adsorb the copper ions.

After rinsing, the samples were treated with 5\% nitric acid solution to dissolve copper ions, and the concentration of copper ions was determined by atomic absorption spectrometry. The results are shown in Fig. 2. The amount of adsorbed copper ions increases exponentially with increasing sulfuric acid concentration, and was 135 $\mathrm{nmol} / \mathrm{cm}^{2}$ on the sample treated with $14 \mathrm{M}$ sulfuric acid solution. Using the copper lattice constant, $0.362 \mathrm{~nm}$, the thickness of the copper thin film formed after the reduction process was estimated to be $10 \mathrm{~nm}$.

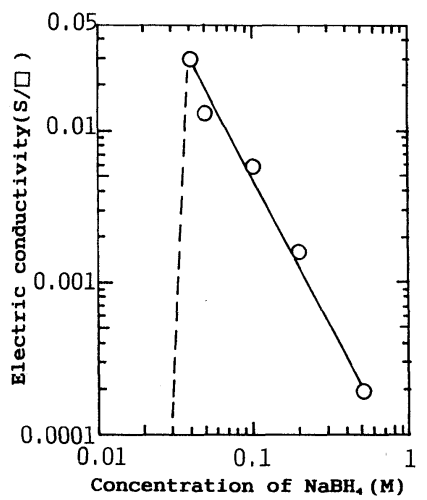

Fig. 3 Relation between concentration of $\mathrm{NaBH}_{4}$ and electric conductivity of epoxy laminate surface treated with reducing process ( $\mathrm{RT}, 3 \mathrm{~min}$ ).

The test samples adsorbed copper ions were reduced with sodium tetrahydroborate solutions for three minutes. Fig. 3 shows the results of the surface conductivity. The maximum value of the conductivity of the test sample was $0.030 \mathrm{~S}$ $/ \square(33 \Omega / \square)$ at $0.04 \mathrm{M}$ sodium tetrahydroborate, and the surface appeared to be bright metallic copper. Processes mentioned above, that is, the introduction of an ion exchange group to a plastic substrate, adsorption of metal ions, and the conversion of adsorbed ions to metals, metal oxides and metal sulfides, are also expected for the metallization of plastics, preparation of the compound semiconductor and metallic cluster.

\section{Conclusion}

A new conducting method for an epoxy laminate was proposed in this paper. The sulfo group, as a cation exchange group, was introduced onto the epoxy laminate surface though sulfuric acid treatment. The amount of adsorbed copper ions increased with increasing sulfuric acid concentration, and was $135 \mathrm{nmol} / \mathrm{cm}^{2}$ on the sample treated with $14 \mathrm{M}$ sulfuric acid solution at $60{ }^{\circ} \mathrm{C}$ for three minutes. The thickness of the copper thin film formed after the reduction process was estimated to be $10 \mathrm{~nm}$. The conductivity of the sample was $0.030 \mathrm{~S} / \square(33 \Omega / \square)$. This process should be expected for formation of new conducting films.

(Received March 21, 1995 ; Accepted April 17, 1995)

\section{References}

1) M. Toyonaga ; Electronic Circuit \& Packaging Technology, 8, 47 (1993)

2) R. M. Silverstein, G. C. Bassler, and T. C. Morrill ; Spectrometric Identification of Organic Compounds, Fifth Edition, p.123 (Translation from English language edition published by John Wiley, New York, 1991) 